Article

\title{
Analysis of Potential Use of Linear Fresnel Collector for Direct Steam Generation in Industries of the Southwest of Europe
}

\author{
Francisco José Sepúlveda * $\mathbb{D}^{\mathbb{D}}$, María Teresa Miranda $\mathbb{D}$, Irene Montero $\mathbb{D}$, José Ignacio Arranz $\mathbb{D}^{\mathbb{D} \text {, }}$ \\ Francisco Javier Lozano, Manuel Matamoros and Paloma Rodríguez \\ Department of Mechanical Engineering, Energy and Materials, Industrial Engineering School, University of \\ Extremadura, Avenue Elvas s/n, 06006 Badajoz, Spain; tmiranda@unex.es (M.T.M.); imontero@unex.es (I.M.); \\ jiarranz@unex.es (J.I.A.); flozanocortes@unex.es (F.J.L.); manuelmp@unex.es (M.M.); palomard@unex.es (P.R.) \\ * Correspondence: fsepulveda@unex.es; Tel.: +34-924-289-600 (ext. 86712)
}

Received: 1 October 2019; Accepted: 22 October 2019; Published: 24 October 2019

\begin{abstract}
Industry sector has an important impact on primary energy consumption at the international level, and solar energy constitutes a real alternative to cover these energy needs partially. Among thermosolar concentration technologies, Linear Fresnel Collector (LFC) technology has some advantages that make it more accessible to industries. With the aim of providing new tools for easier decision-making processes, in the present work, several energy audits were carried out in industries (located in the south-west of Europe, with considerable steam consumptions), quantifying thermal and energy consumptions and defining both work schedules and seasonality. Afterwards, a comparison based on three factors was carried out: Thermal consumption regarding total industry consumption, the performance of the work during the solar schedule, and the quantification of the monthly average concentrated energy for a certain LFC facility. The analysis carried out according to these criteria showed different results for each case, making a global assessment necessary to suitably ponder each factor. This analysis ranked tomato industries as the most suitable for LFC technology, due to the fact that their main operating period was during the months with the highest solar isolation, and the solar schedule was completely integrated in a 24-h working day. Also, industrial waxes and laundries showed a good combination of both facts.
\end{abstract}

Keywords: renewable energy; energy simulation; SHIP; season; solar time ratio; schedule; industry analysis

\section{Introduction}

There has been a constant increase in energy consumption over the last century. Both energy demand and $\mathrm{CO}_{2}$ emissions are expected to rise to $60 \%$ in 2030. Global oil consumption has grown $20 \%$ since 1994, and it is expected to grow 1.6\% annually [1]. Moreover, global warming and greenhouse gas emissions also generate problems that make the transition from fossil fuels to green energies more important than ever [2-4]. Several international agreements have been established regarding this issue with various objectives: Decrease greenhouse gas emissions a minimum of $40 \%$ at a national level and a reach $32 \%$ share of renewables in gross final energy consumption [5]. In that sense, solar energy is a real alternative to cover a part of the energy needs of our society [6,7]. Amongst many advantages, renewable energies offer a more stable evolution of prices compared to fossil fuels, due to the limited supply capacity and the dependency on the international market of the fossil fuels [8-14].

On the other hand, industry accounts for approximately $40 \%$ of primary energy consumption globally in 2019 [15]. Similarly, at a European level, industry demands 37\%, while, in Spain, it represents 
$26 \%$ of primary energy consumption [16]. Furthermore, heat generation processes in industry constitute $54 \%$ of the total energy consumption in Europe in contrast with $17 \%$ of the total energy consumption corresponding to electric uses. This proportion of energy use justifies the implementation of solar thermal-based systems [17].

Solar thermal systems harness solar energy for heating, either as hot water for domestic use-domestic hot water and heating-as a heating source for fluids in industrial processes or as steam to produce mechanical energy in a turbine to obtain electrical energy. Solar thermal systems may have concentrators to direct solar isolation that strikes the capturing surface area towards a smaller area (absorber area). This configuration obtains higher temperatures in the heat transfer fluid. These devices achieve solar concentration using specular reflection; thus, only direct isolation is used.

There are two different technologies that concentrate direct solar isolation: Point focus type, that concentrates isolation into a single point-solar power tower or Dish-Stirling system-and linear focus type, which concentrates isolation into a linear receptor. Linear focus type reaches higher temperatures, because it concentrates isolation into a larger area. There are two types of linear focus collectors: Parabolic trough collector (PTC) and linear Fresnel collectors [18,19].

Several studies have shown LFC (Linear Fresnel Collector) optical quality and thermal efficiency is slightly lower than in the case of PTC, due to the high influence of the angle of incidence and the cosine factor. Nevertheless, the consecution of higher concentrations or a better optical efficiency does not imply that this system is suitable for any use [20,21]. In that sense, LFC technology shows a number of advantages compared to PTC, such as its greater structural simplicity and the use of flat mirrors (or with low curvature). These aspects considerably reduce manufacture costs. Plus, they require low energy to follow the apparent motion of the sun-only the mirrors have to rotate-and the separation between the concentrator and the heat carrier fluid line remove the problems concerning flexible or rotative connections between concentrators, making the maintenance easier [22-26]. This way, and given the need for implementing efficient, economical and renewable energy sources in industrial applications, LFC technology can comply with these targets, currently finding certain evidences of its implementation in different production plants, for example, in pharmaceutical industry in Jordan [27], in agro-food industry in Italy [28] or automobile manufacturing in Germany [29].

Although the possibilities of solar energy for industrial processes has been widely proved and provided satisfactory results, the role of solar energy in industry is still reduced, possibly due to the lack of knowledge about this technology by the final user. Because of that, it is necessary to carry out new research works to provide simple and direct information about the advantages of the use of this technology. Thus, Shahjadi Hisan Farjana et al. [17] carried out a study about possible industrial processes that could accommodate heating systems through solar processes, pointing out the high volume of thermal energy required in drying, washing, cleaning, water heating, pasteurization, sterilization and other food processes. In another work by the same authors, they identified 10 countries where the use of this kind of system is highlighted—analyzing the potential of integration [30]. Laveet Kumar et al. [31] also classified current industrial process-heat system based on solar collector technologies and heat demand temperatures for the identification of typical applications for solar process heat, stablishing that solar thermal technologies can be used for a variety of industrial applications for sustainable energy system, although solar thermal energy storage is necessary.

Likewise, for the implementation of solar concentration technologies in industries, it is necessary to know a number of factors, such as the location and the space available, temperature and working pressures, energy use, etc. Tengjia et al. [32] specified interesting sectors to use this technology, such as tobacco, food processing, textile, chemical, pharmaceutical, wood, plastics or rubber industries, among others.

Schweiger et al. [33] wrote a state-of-the-art review about the potential of solar heat in industrial processes, in which they showed an interesting list of solar industrial process heat projects. They carried out TRNSYS simulations for five cities in Spain and Portugal, and an estimation of the efficiency of solar process heat plants in the Southern European climate are given for different collector technologies. 
In the same way, Lauterbach et al. [34] calculated the potential of solar heat for industrial processes in Germany and selected 11 sectors that were identified to be most promising for the use of solar heat, such as chemicals, food and beverages, motor vehicles, paper, fabricated metal, machinery and equipment, rubber and plastic, electrical equipment, textiles, printing and wood.

Therefore, there are several works concerning the field of solar heat potential for industrial processes, although these papers mainly cover industrial processes and their energy consumption. Nonetheless, seasonality and work schedule must be considered for steam production. This allows to estimate the potential concentrated energy these systems—especially LFC—produce during normal operating conditions. Thus, a new indicator is introduced to study the industries solar heat potential.

On the basis of the above, in the present work, a series of simplified energy audits in industries located in the southwest of Europe were carried out, in order to quantify the thermal and energy consumption and define both working schedules and seasonality. Afterwards, a procedure was established to determine the grade of the susceptibility of industries for the implementation of LFC systems to support traditional systems of thermal energy generation. This procedure was based on the study of three factors: Thermal consumption compared to the total in the industry, performance of the work during the solar schedule, and quantification of the monthly average concentrated energy for a certain LFC facility. In the latter case, a set of energy simulation studies was carried out, paying attention to the optical yield variation and different direct isolation levels throughout the year.

\section{Materials and Methods}

\subsection{Selection of Industries}

Different industries with considerable steam consumptions, from the southwest of Europe, were selected. The most relevant data for the analysis were defined, such as production, working hours, seasonality and energy consumption, among others.

Table 1 shows the selected industries for this study, as well as relevant data concerning their capacity in their corresponding sector.

Table 1. Industries selected for the study.

\begin{tabular}{ccc}
\hline Industries & Capacity & Industrial Sector \\
\hline Small capacity meat industry & 5800 pigs/year & Transforming \\
Medium capacity meat industry & 116,000 pigs/year & Transforming \\
High capacity meat industry & 170,000 pigs/year & Transforming \\
Processing nuts industry & 180 Tons nuts/year & Transforming \\
Fat processing industry & 19,800 Tons fats/year & Transforming \\
Rice industry & 34,500 Tons rice/year & Transforming \\
Tomato industry 1 & 420,000 Tons tomato/year & Transforming \\
Tomato industry 2 & 53,500 Tons tomato/year & Transforming \\
Cleaning products manufacturer & 90,000 Tons cleaning products/year & Manufacturer \\
Industrial waxes manufacturer & 13,000 Tons waxes/year & Manufacturer \\
Cardboard packaging manufacturer & 96,000 $\mathrm{m}^{2}$ cardboard/year & Manufacturer \\
Medium capacity laundry & 1650 Tons clothes/year & Services \\
High capacity laundry & 2000 Tons clothes/year & Services \\
\hline
\end{tabular}

\subsection{Definition of the Criteria Used}

The following criteria were defined:

- Thermal energy ratio $\left(R_{T E}\right)$, which relates the thermal energy consumed and the total energy demand by each industry analyzed.

- Solar time ratio $\left(R_{S T}\right)$ relates to the part of the working schedule of industries matches the hours of sunlight (with solar isolation). 
- Monthly average concentrated energy $(E, \mathrm{kWh})$ : This variable quantifies the average solar energy that an LFC system could concentrate during the normal performance of the industry.

\subsection{Thermal Energy Ratio}

Through the analysis of thermal and electrical energy bills of each industry, the annual consumptions were obtained, corresponding to each kind of energy: Thermal Energy, $T E$, in $\mathrm{kWh}$ and Electrical Energy, $E E$, in $\mathrm{kWh}$. Afterwards, the thermal energy ratio was determined according to Equation (1). Thus, a high value of $R_{T E}$ can be interpreted as the high suitability of a certain industry for the implementation of LFC technology,

$$
R_{T E}=\frac{T E}{T E+E E}
$$

\subsection{Solar Time Ratio}

Concentrated solar power technology limits its use to the hours when the sun is present. Thus, Table 2 shows the average values of sunrise and sunset times, which limit the solar schedule (as a reference, data corresponding to the 15th of each month for the city of Cáceres, located in the southwest of Spain, were used) [35].

Table 2. Average values of sunrise and sunset used in the study.

\begin{tabular}{ccc}
\hline Month & Sunrise & Sunset \\
\hline Jan. & $08: 44$ & $18: 26$ \\
Feb. & $08: 17$ & $19: 02$ \\
Mar. & $07: 37$ & $19: 32$ \\
Apr. & $07: 48$ & $21: 03$ \\
May & $07: 11$ & $21: 33$ \\
Jun. & $06: 58$ & $21: 54$ \\
Jul. & $07: 11$ & $21: 52$ \\
Aug. & $07: 38$ & $21: 21$ \\
Sep. & $08: 07$ & $20: 34$ \\
Oct. & $08: 35$ & $19: 46$ \\
Nov. & $08: 10$ & $18: 10$ \\
Dec. & $08: 39$ & $18: 03$ \\
\hline
\end{tabular}

This way, it is possible to determine the fraction of time in which the working schedule overlaps with the solar schedule. This fraction of time is called solar ratio, $R_{S T}$, and it was obtained through Equation (2), where $S P_{j}$ and $T P_{j}$ (hours) are the production times in the solar schedule for each month $j$, and $n$ is the number of months of operation for the industry. On this basis, the industries whose working schedule overlaps with the solar schedule to a larger extent will benefit from this technology to a greater extent,

$$
R_{S T}=\frac{\sum_{j=1}^{n}\left(\frac{S P}{T P}\right)_{j}}{n} .
$$

\subsection{Monthly Average Concentrated Energy}

The distribution of the industries production throughout the year was determined using the energy studies detailed in the previous section. This is relevant, as LFC technology will show different yields depending on the time of the year when the industry works. Thus, an energy simulation model was implemented, exclusively focused on the optical behavior of a generic LFC plant. The simulation was done by using Matlab [36], a software that combines an improved environment for the iterative analysis and design processes with a programming language. A generic LFC plant for a 
steam generation was defined, whose location and main characteristics are shown in Table 3. Moreover, Figure 1 shows a graphical representation of the LFC used.

Table 3. Geographic and sizing data used.

\begin{tabular}{ccc}
\hline \multirow{3}{*}{ Geographic Data } & Latitude & $39.467^{\circ} \mathrm{N}$ \\
& Longitude & $-6.333^{\circ} \mathrm{W}$ \\
& Orientation & $\mathrm{N}-\mathrm{S}$ \\
\hline & LFC (Linear Fresnel Collector) modules & 8 \\
& Mirror rows & 10 \\
Sizing Data & Mirror length $(\mathrm{m})$ & 6.0 \\
& Mirror width $(\mathrm{m})$ & 0.5 \\
& Distance between mirrors $(\mathrm{m})$ & 0.1 \\
& Absorber tube height $(\mathrm{m})$ & 3.0 \\
\hline
\end{tabular}

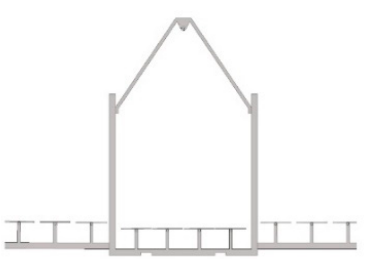

(a)

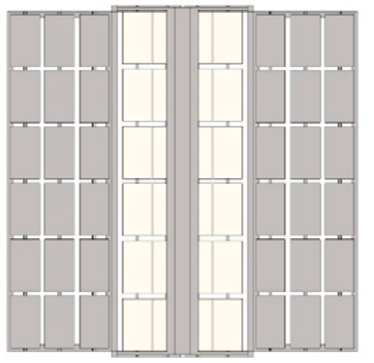

(b)

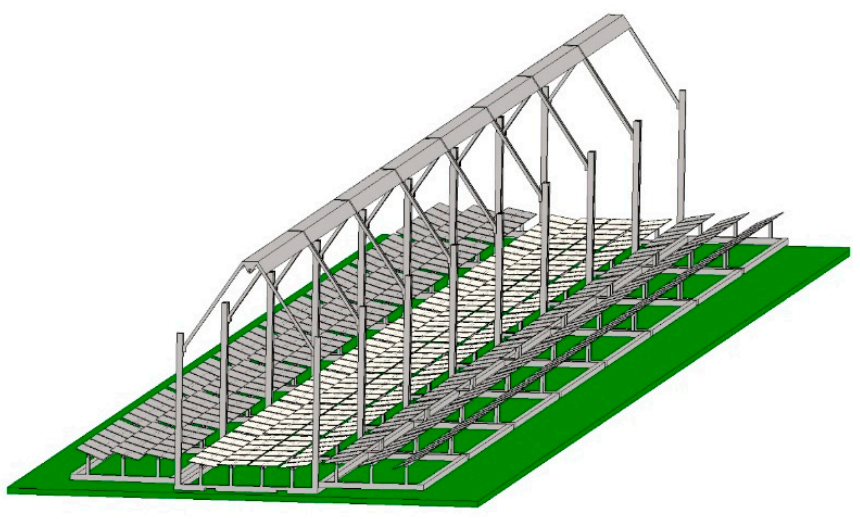

(c)

Figure 1. Front (a) and top view (b) of a module, and 3D diagram of LFC (c).

For the energy simulation, the following considerations were taken into account:

- As the purpose of the plant was the direct steam generation, the calculation was exclusively carried out for the industries seasonality and work schedules for a 7-day week. Not all the companies analyzed operate regularly every day of the week. However, they all do so at some time to cover demand spikes. Therefore, we decided not to take this factor into account in the study, just as scheduled maintenance stops were not considered.

- A time step of $90 \mathrm{~s}$ was considered, obtaining for each case the new position of the sun. Similarly, the optimum angle of the mirrors-which allows the highest incident solar isolation concentration-was modified every $90 \mathrm{~s}$.

- Optical losses were quantified considering the following factors: Shadow between rows, optical losses and non-lite pipe factor. The model used to calculate these losses is based on the procedure described by Pino et al. [37] for an E-O orientation. Thus, it was necessary to make some changes to consider other different orientations. A detailed description of these changes is included in the Annex section.

Concerning the optical losses, a shadow between rows factor, $f_{\text {shading, } i, t}$, is directly related to the total isolation that the field of mirrors can reflect on the absorber tube. Once the shaded area is known, it is divided by the total reflective Surface, according to Equation (3), where $s w_{i, t}(\mathrm{~m})$ is the shaded width of each row of mirrors $i$ for each calculation step $t$, and $L(\mathrm{~m})$ and $A\left(\mathrm{~m}^{2}\right)$ are the length and the area for a row of mirrors of the LFC, respectively; 


$$
f_{\text {shading }, i, t}=1-\frac{s w_{i, t} \cdot L}{A} .
$$

In turn, the solar beam isolation that hits the mirrors is not completely exploited. As the latter reflect the isolation to the absorber tube, the rays of the sun do not strike the mirror surface in a perpendicular position. The difference between the real inclination of the mirror and the one that it should have to make the most of the incident isolation determines the effective surface of the mirror. Optical losses, $f_{o l, i, t}$, are given by the cosine of the angle formed by the solar incidence vector and the direction normal to the surface of the row of mirrors $i$ for each calculation step $\delta_{i, t}$, according to Equation (4),

$$
f_{o l, i, t}=\cos \left(\delta_{i, t}\right) \text {. }
$$

Due to the azimuthal component of the solar disk for each instance, a section of one of the edges of the absorber tube is not illuminated. This effect will be produced in a direction, or the opposite one before the sun reaches the midday and overtakes it, respectively. The length of this non-illuminated section for each calculation step $t, Z_{i, t}(\mathrm{~m})$, will proportionally affect the optical yield, with $L_{a}$ being the length of the absorber tube in the LFC system. Equation (5) allows the calculation of the losses in the non-lite pipe factor, $f_{n l p, i, t}$;

$$
f_{n l p, i, t}=1-\frac{Z_{i, t}}{L_{a}}
$$

Finally, the optical yield $\mu_{i, t}$ for each row of mirrors $i$ and for each calculation step $t$ is given by the product of the above-mentioned factors, as it is shown in Equation (6):

$$
\mu_{i, t}=f_{\text {shading }, i, t} \cdot f_{o l, i, t} \cdot f_{n l p, i, t}
$$

The energy concentrated by each row of mirrors $i$ in each calculation step $t, E_{i, t}(\mathrm{kWh})$, will be given by Equation (7), where $I_{b, t}$ is the beam irradiance $\left(\mathrm{kW} \cdot \mathrm{m}^{-2}\right), \rho_{p r}$ and $f_{c l} \_p r$, are the reflectance and the cleanliness factor of the primary mirrors, $\rho_{s d}$ and $f_{c l}$ sd are the reflectance and the cleanliness factor of the secondary receiver, and $T(h)$ is the duration of each time step,

$$
E_{i, t}=I_{b, t} \cdot A \cdot \mu_{i, t} \cdot \rho_{p r} \cdot f_{c l \_p r} \cdot \rho_{s d} \cdot f_{c l \_s d} \cdot T .
$$

$I_{b, t}$ data were provided by Meteonorm software (7.1 version) [38], that offers a unique combination of reliable data sources and sophisticated calculation tools. It provides access to typical years and historical time series. Figure 2 shows the values of the beam, diffuse and global insolation (sum of the first two) on a horizontal plane $\left(\mathrm{kWh} \cdot \mathrm{m}^{-2}\right)$, obtained throughout a year for the location showed in Table 3.

Finally, the concentrated energy values for each calculation step $t, E_{t}(\mathrm{kWh})$, and month, $E_{j}(\mathrm{kWh})$, and the monthly average considering the number of working months, $E(\mathrm{kWh})$, are obtained by Equations (8)-(10), respectively. On the basis of this, the industries that will benefit from these criteria will be those that, on one hand, show higher optical yields, and, on the other hand, intensify their production during the months with the highest solar isolation,

$$
\begin{aligned}
& E_{t}=\sum_{i=1}^{r} E_{i, t}, \\
& E_{j}=\sum_{t} E_{t}, \\
& E=\frac{\sum_{j=1}^{n} E_{j}}{n} .
\end{aligned}
$$




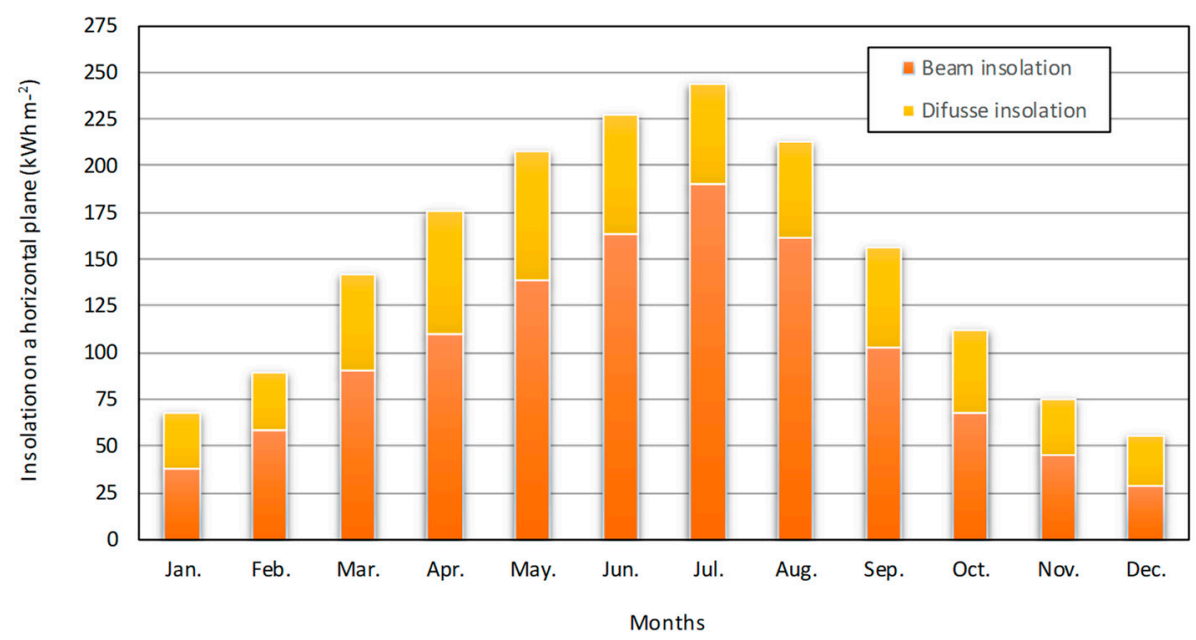

Figure 2. Beam, diffuse and global insolation on a horizontal plane for the selected location $\left(\mathrm{kWh} \cdot \mathrm{m}^{-2}\right)$.

\section{Results and Discussion}

\subsection{Summary of the Energy Studies Carried Out}

Table 4 shows the stages and processes that require thermal energy, as well as the working pressure of the steam boiler, schedule, seasonality and energy consumptions.

Table 4. Data from studies to industries.

\begin{tabular}{|c|c|c|c|c|c|c|}
\hline Industries & Processes & Pressure (bar) & Schedule & Seasonality & $T E(\mathrm{kWh})$ & $E E(\mathrm{kWh})$ \\
\hline $\begin{array}{l}\text { M.C. Laundry } \\
\text { H.C Laundry }\end{array}$ & $\begin{array}{l}\text { Washing } \\
\text { Drying } \\
\text { Ironing }\end{array}$ & $\begin{array}{l}10 \\
13\end{array}$ & $\begin{array}{l}\text { 08:00-22:00 } \\
\text { 06:00-14:00 }\end{array}$ & 12 months & $\begin{array}{l}1,891,604 \\
3,740,652\end{array}$ & $\begin{array}{l}242,956 \\
623,148\end{array}$ \\
\hline $\begin{array}{l}\text { Tomato ind. } 1 \\
\text { Tomato ind. } 2\end{array}$ & $\begin{array}{l}\text { Preheating } \\
\text { Evaporating } \\
\text { Sterilization }\end{array}$ & $\begin{array}{c}12 \\
9\end{array}$ & $\begin{array}{l}24 \mathrm{~h} \\
24 \mathrm{~h}\end{array}$ & $\begin{array}{l}2 \text { months } \\
\text { during } \\
\text { summer }\end{array}$ & $\begin{array}{c}50,000,000 \\
130,000,000\end{array}$ & $\begin{array}{c}7,000,000 \\
17,000,000\end{array}$ \\
\hline $\begin{array}{l}\text { S.C. Meat ind. } \\
\text { M.C. Meat ind. } \\
\text { H.C. Meat ind. }\end{array}$ & $\begin{array}{l}\text { Scalding } \\
\text { Baking } \\
\text { Cleaning }\end{array}$ & $\begin{array}{l}7 \\
6 \\
6\end{array}$ & $\begin{array}{l}06: 00-14: 00 \\
06: 00-14: 00 \\
06: 00-22: 00\end{array}$ & 12 months & $\begin{array}{c}405,600 \\
2,493,288 \\
7,000,000\end{array}$ & $\begin{array}{c}794,667 \\
1,079,184 \\
13,000,000\end{array}$ \\
\hline $\begin{array}{l}\text { Fat processing } \\
\text { industries }\end{array}$ & $\begin{array}{l}\text { Fusion } \\
\text { Drying }\end{array}$ & 6 & $24 \mathrm{~h}$ & 12 months & $5,952,985$ & $1,621,828$ \\
\hline Rice industry & Vaporization & 10 & $24 \mathrm{~h}$ & 12 months & $13,061,657$ & $3,486,770$ \\
\hline $\begin{array}{l}\text { Cleaning products } \\
\text { man. }\end{array}$ & $\begin{array}{c}\text { Heating } \\
\text { Homogenization }\end{array}$ & 7 & $24 \mathrm{~h}$ & 12 months & $1,890,000$ & 780,000 \\
\hline $\begin{array}{c}\text { Industrial waxes } \\
\text { man. }\end{array}$ & Heating & 9 & $24 \mathrm{~h}$ & 12 months & $12,500,000$ & $1,200,000$ \\
\hline $\begin{array}{c}\text { Cardboard } \\
\text { packaging man. }\end{array}$ & Undulation & 15 & $24 \mathrm{~h}$ & 12 months & $12,688,068$ & $5,079,228$ \\
\hline $\begin{array}{l}\text { Processing nuts } \\
\text { industry }\end{array}$ & Drying & 6 & 08:00-20:00 & $\begin{array}{l}6 \text { months } \\
\text { from July to } \\
\text { December }\end{array}$ & 121,680 & 108,738 \\
\hline
\end{tabular}

\subsection{Thermal Energy Ratio}

Figure 3 shows the classification obtained according to the thermal energy ratio criterion. The industry that showed the highest percentage was the industrial waxes manufacturer, because it uses a considerable amount of steam to avoid the solidification of wax during the production process (passing through pipes, etc.). The following industries are the industrial laundries and tomato industries. The former showed high thermal energy demands during washing, drying and ironing. The latter, spent thermal energy in processes such as pre-heating, evaporation and sterilization. 


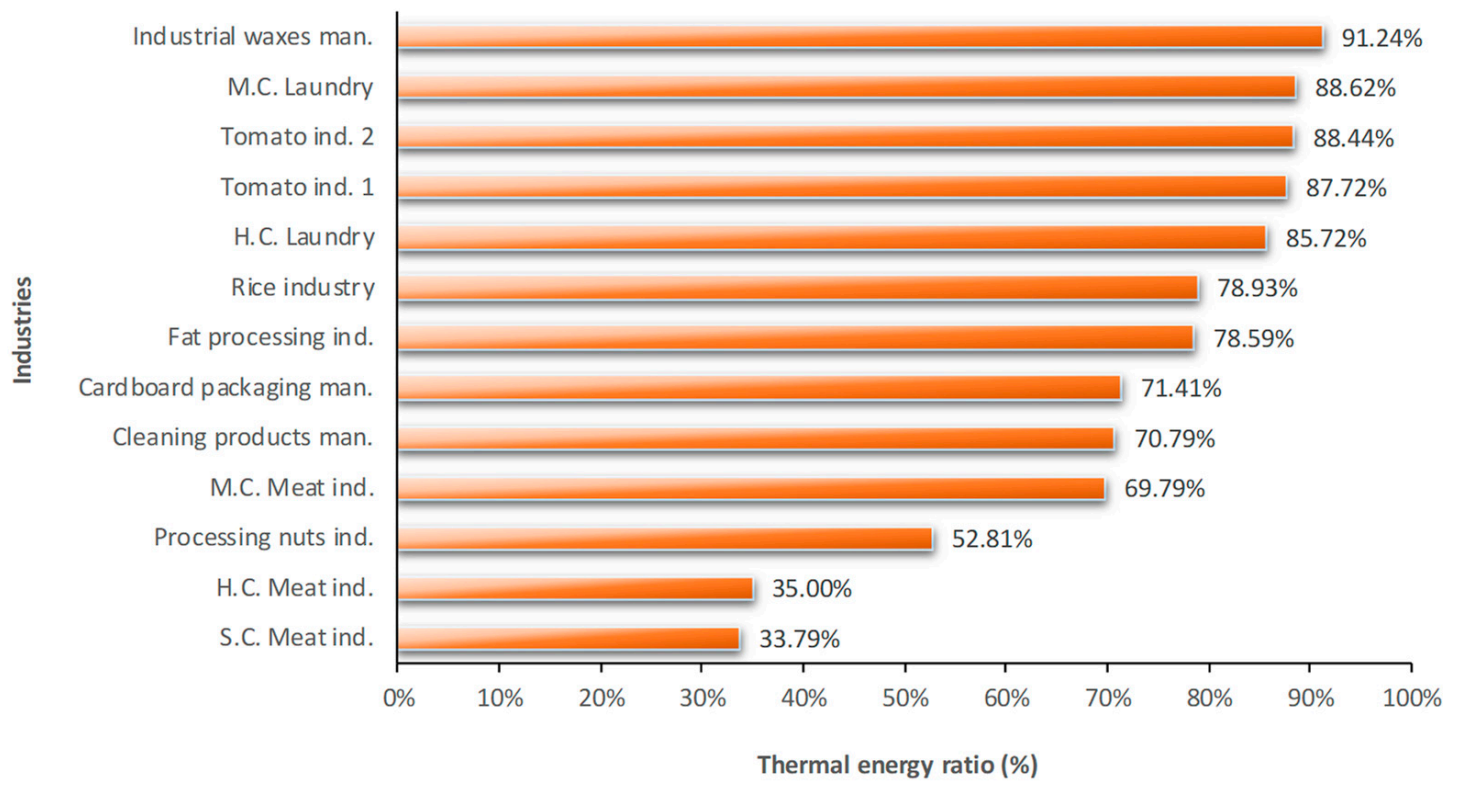

Figure 3. Classification according to thermal energy ratio.

At an intermediate level, there are industries that work with rice, cardboard packaging and chemical products, where the drying, corrugation and homogenization, respectively, represent a considerable thermal consumption, although not as high as in the case of the former. At a final level, the meat industries can be found, where the electricity use was higher than the thermal consumption for high and small capacity industries.

In that sense, 11 out of 13 industries that were studied exceeded 50\% thermal energy ratio, possibly being a good starting point for LFC implementation. Nevertheless, values higher than $30 \%$ also represent a considerable part of production costs in industries; their relevance should not be underestimated.

\subsection{Solar Time Ratio}

Table 5 shows the results obtained according to the solar time ratio criterion.

Table 5. Percentage of production time in solar time.

\begin{tabular}{ccccccccccccc}
\hline Industries & Jan. & Feb. & Mar. & Apr. & May & Jun. & Jul. & Aug. & Sep. & Oct. & Nov. & Dec. \\
\hline S.C. meat industry & 65.8 & 71.5 & 79.8 & 77.5 & 85.2 & 87.9 & 85.2 & 79.6 & 73.5 & 67.7 & 72.9 & 66.9 \\
\hline M.C. meat industry & 65.8 & 71.5 & 79.8 & 77.5 & 85.2 & 87.9 & 85.2 & 79.6 & 73.5 & 67.7 & 72.9 & 66.9 \\
\hline H.C. meat industry & 60.6 & 67.2 & 74.5 & 82.8 & 89.8 & 93.3 & 91.8 & 85.7 & 77.8 & 69.9 & 62.5 & 58.8 \\
\hline Processing nuts ind. & - & - & - & - & - & - & 100.0 & 100.0 & 99.0 & 93.2 & 83.3 & 78.3 \\
\hline Fat processing industry & 40.4 & 44.8 & 49.7 & 55.2 & 59.9 & 62.2 & 61.2 & 57.2 & 51.9 & 46.6 & 41.7 & 39.2 \\
\hline Rice industry & 40.4 & 44.8 & 49.7 & 55.2 & 59.9 & 62.2 & 61.2 & 57.2 & 51.9 & 46.6 & 41.7 & 39.2 \\
\hline Tomato industry 1 & - & - & - & - & - & - & 61.2 & 57.2 & - & - & - & - \\
\hline Tomato industry 2 & - & - & - & - & - & - & 61.2 & 57.2 & - & - & - & - \\
\hline Cleaning prod. & 40.4 & 44.8 & 49.7 & 55.2 & 59.9 & 62.2 & 61.2 & 57.2 & 51.9 & 46.6 & 41.7 & 39.2 \\
\hline Industrial waxes & 40.4 & 44.8 & 49.7 & 55.2 & 59.9 & 62.2 & 61.2 & 57.2 & 51.9 & 46.6 & 41.7 & 39.2 \\
\hline Cardboard packaging & 40.4 & 44.8 & 49.7 & 55.2 & 59.9 & 62.2 & 61.2 & 57.2 & 51.9 & 46.6 & 41.7 & 39.2 \\
\hline M.C. Laundry & 69.3 & 76.8 & 82.4 & 93.2 & 96.8 & 99.3 & 61.2 & 57.2 & 88.9 & 79.9 & 71.4 & 67.1 \\
\hline H.C. Laundry & 65.8 & 71.5 & 79.8 & 77.5 & 85.2 & 87.9 & 90.9 & 87.4 & 73.5 & 67.7 & 72.9 & 66.9 \\
\hline
\end{tabular}


Figure 4 shows the classification obtained. The best-rated industry, according to this criterion, was the processing nuts industry. Its working schedule, from 08:00 to 20:00 from July to December, coincides with sunrise and sunset to a larger extent. The second best-rated industry is the laundry industry, which offers its service throughout the year, albeit the working schedule is extended during the summer, due to the increase in the demand. In third place, meat industries can be found, which operate throughout the year. The beginning of the working day is similar throughout the year or during campaigns. This is the case of the tomato industry. This fact provokes that sunshine hours can only be exploited during half of the work schedule, and, because of this, their ranking is poor.

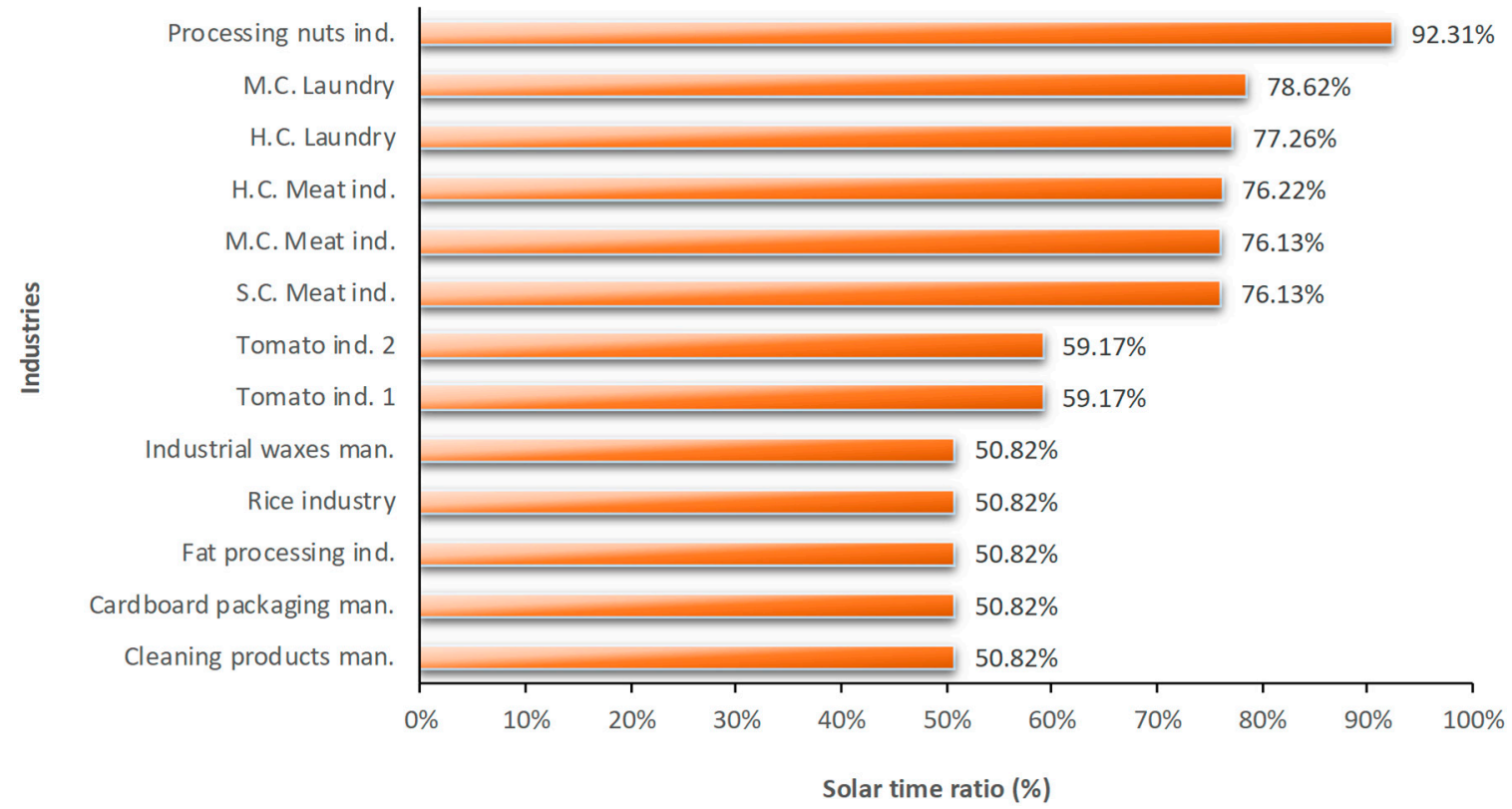

Figure 4. Classification according to solar time ratio.

On the other hand, there were many differences when thermal energy ratio was considered. Process in the nuts industry showed a high suitability value for solar schedule, even though its thermal processes only imply $53 \%$ of total energy demand. The same happens in meat industries, with solar time ratios above $75 \%$ and having a low ranking concerning thermal energy ratio. Instead, the analyzed laundries showed very high values in both cases, which implies high suitability when implementing LFC technologies.

\subsection{Monthly Average Concentrated Energy}

As an example of the simulation studies carried out, Figure 5 shows the results obtained for one of the industries visited, namely, the medium capacity laundry. It could be observed how the monthly concentrated energy considerably increased during the months with the highest isolation $(23,363 \mathrm{kWh}$ in July, whereas, December showed $2782 \mathrm{kWh}$, that is, 8.4 times greater compared to the latter). Instead, the monthly optical yields were kept between 40 and $52 \%$ in the year. These data were within the range obtained by other authors. Thus, Kincaid et al. [39] found that the yearly optical efficiency, according to their models, was $40 \%$. Mohamed $\mathrm{H}$. Ahmed et al. [40] simulated the optical performance of a linear Fresnel obtaining 67\% with their optical model and 38.8\% accounting the sun-to-electric annual average efficiency. According to Ghodbane et al. [41], the optical efficiency of the solar reflector in their simulation reaches $53.7 \%$.

Therefore, the variation in optical yield was significantly lower than the registered one for the concentrated energy, demonstrating the importance of beam isolation in energy analysis. 


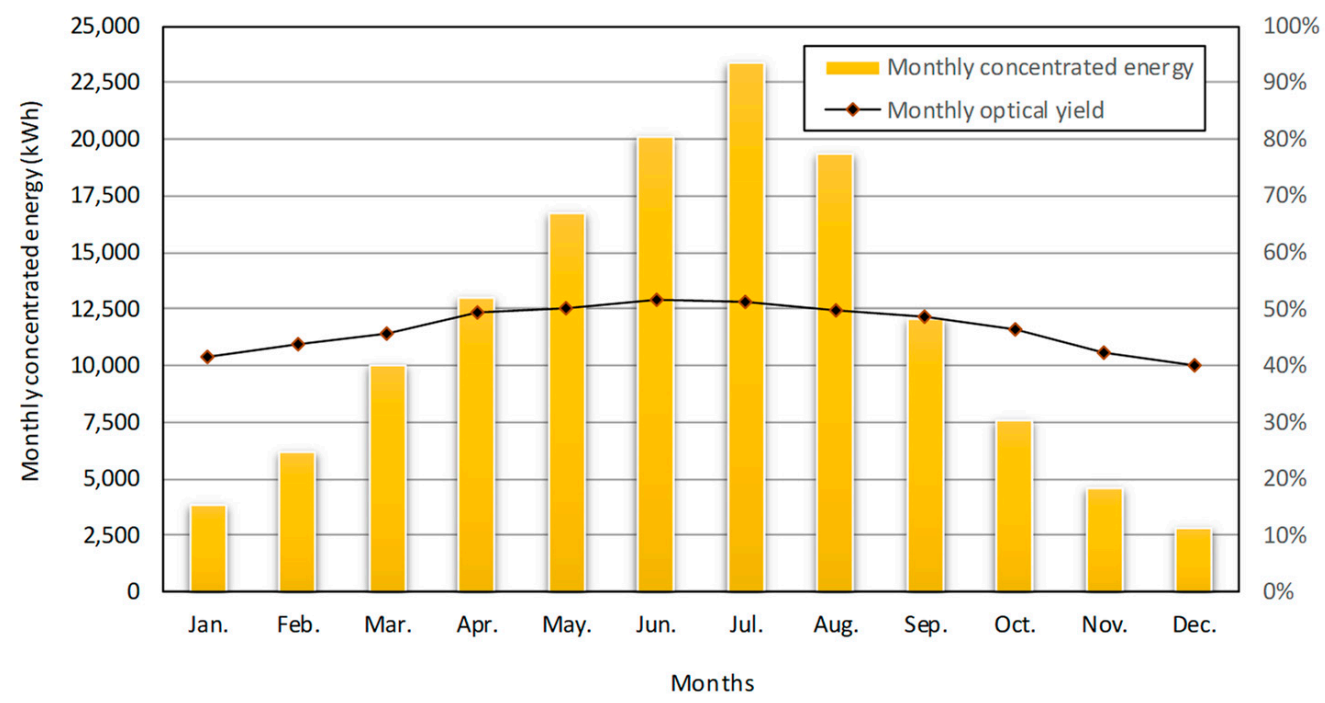

Figure 5. Monthly concentrated energy and optical yield obtained for medium capacity laundry.

Therefore, and due to the fact that solar time ratio was directly incorporated to the energy simulations carried out, Figure 6 relates the criteria used-thermal energy ratio vs monthly average concentrated energy - and graphically shows the susceptibility level for the different industries for the implementation of LFC technology.

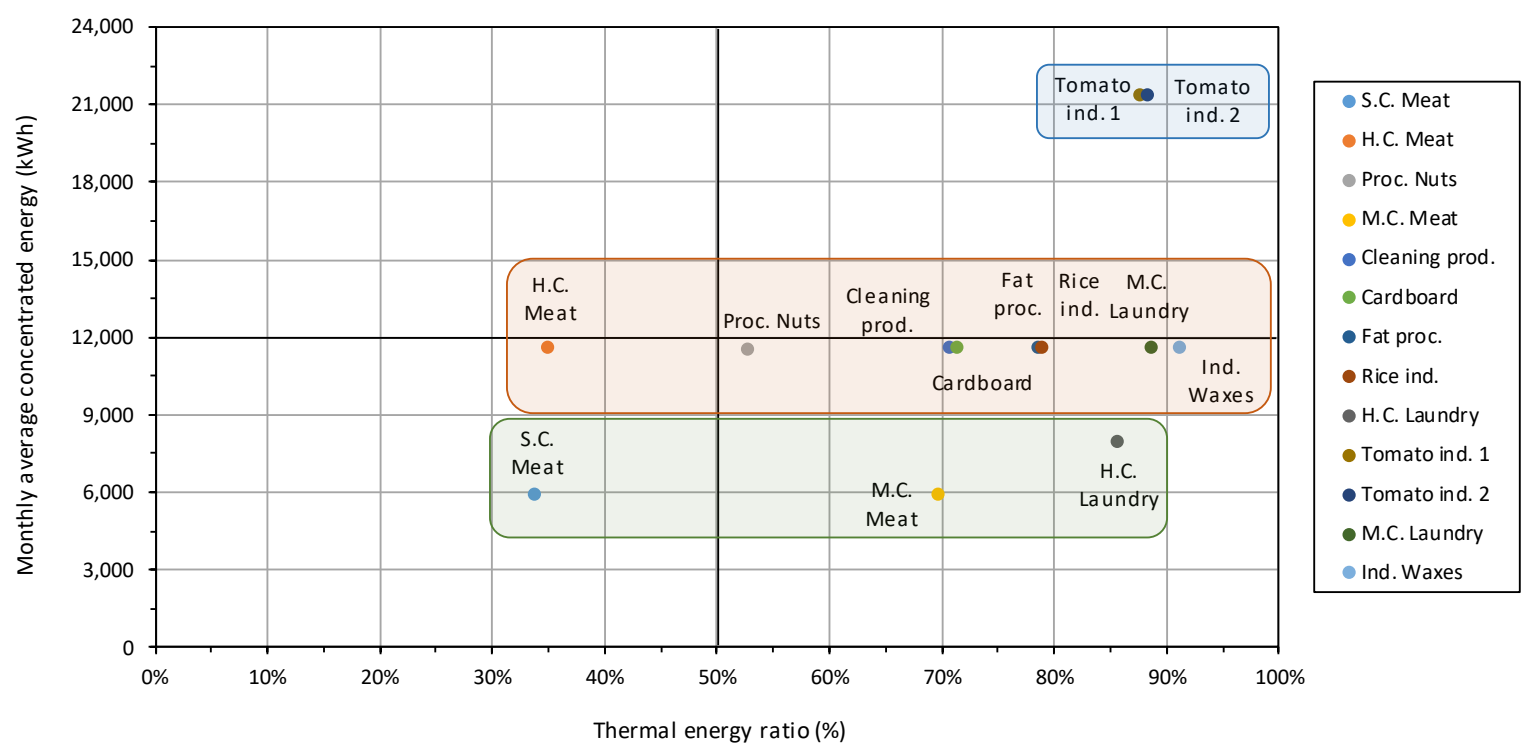

Figure 6. Thermal energy ratio vs monthly average concentrated energy.

Thus, in the upper-right corner, the industries that showed higher suitability to implement this technology were located. In this case, tomato industries should be highlighted, due to the great yield or performance that LFC technology showed during the seasonality of these companies-July and August-and the high specific weight of the processes that demand thermal energy (around $90 \%$ ). In turn, they have a working schedule that includes all the available sunshine hours (solar time ratio of $59 \%)$.

There is a second group of industries with monthly average concentrated energy values close to $12,000 \mathrm{kWh}$, sharing seasonality levels and working hours, and whose thermal energy ratio varied from $35 \%$ (high capacity meat) and $92 \%$ (industrial waxes manufactures). In these cases, thermal energy ratio is a decisive parameter for LFC implementation. Among the laundries, the medium capacity 
laundry showed a higher monthly average concentrated energy value, as its work schedule goes to 22:00, and can make the most of the solar schedule.

Thirdly, there is a third group, composed of the high capacity laundry and the medium and small capacity meat industries, which showed monthly average concentrated energy values below 9000 $\mathrm{kWh}$. In turn, the lower values of thermal energy ratio were due to higher use of electrical energy for refrigeration.

Finally, it should be pointed out that the joint analysis of the energy simulation studies and the thermal energy ratio showed further information than in the case of a separate study of both criteria. Thus, for industries that work with the same seasonality and schedules, thermal energy ratio might be a differentiating factor for decision-making.

\section{Conclusions}

The most relevant findings in the present work were the following:

- The analysis carried out following different criteria showed that a global analysis is necessary to suitably weight both the energy and thermal needs and the coincidence with the solar schedule.

- The operating characteristics of all the industries analyzed are suitable for LFC technology. In fact, they showed thermal energy ratios above $30 \%$-significant possibilities of savings in energy costs related to thermal processes - and solar time ratios above 50\%-high coincidence between solar and work schedules.

- The joint analysis ranked tomato industries as the most suitable ones for LFC technology, due to their operating work during the months with the highest solar isolation, integrating the solar schedule in a 24-h working day. Also, industrial waxes manufacturer and laundries, especially in the case of medium capacity industries, showed a good combination of both factors.

\section{Annex}

In this section, the modifications applied to the optical model by Pino et al. [37] to consider different orientations to E-O are included. Even though optical losses and non-lite pipe factor do not depend on orientation, for the determination of the shadow between rows, it is necessary to consider some additional cases. Thus, for an N-S orientation, like the one used in this work-Y axis in Figure 7-the row of mirrors are located on the left of this axis and also casts shadows on the row of mirrors on the right at certain periods of the day.

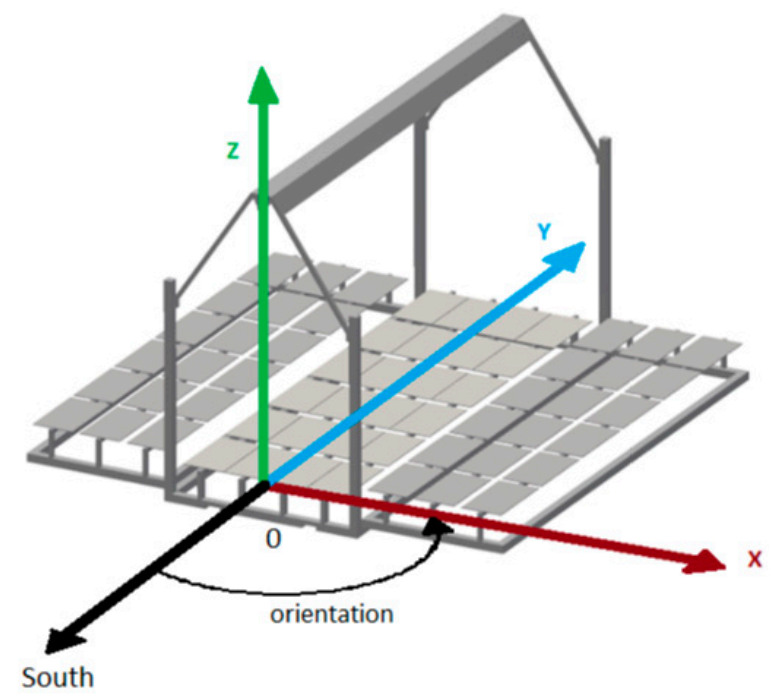

Figure 7. Axis defined for Fresnel module. 
Thus, two new cases, when the angle of inclination of the shaded mirror, incl_ $i$, is negative, were defined. In turn, Figure 8 represents the case when the row of mirrors that casts shadows has a negative inclination angle, calculating the shadow cast from the position of point D. On the other hand, Figure 9 represents the complementary case, in which the row of mirrors that casts shadows have a positive inclination angle, calculating the shadow cast from the position of the other edge of the row, that is, point $\mathrm{F}$.

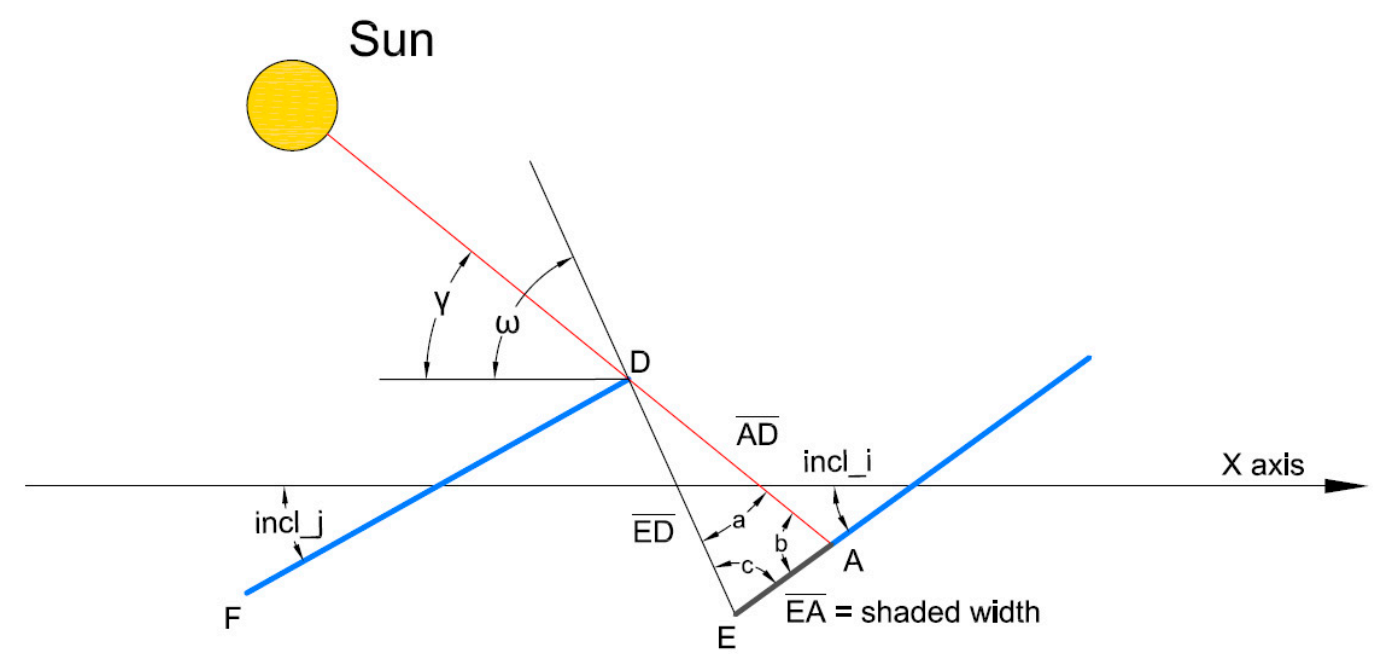

Figure 8. Both mirrors with negative inclination.

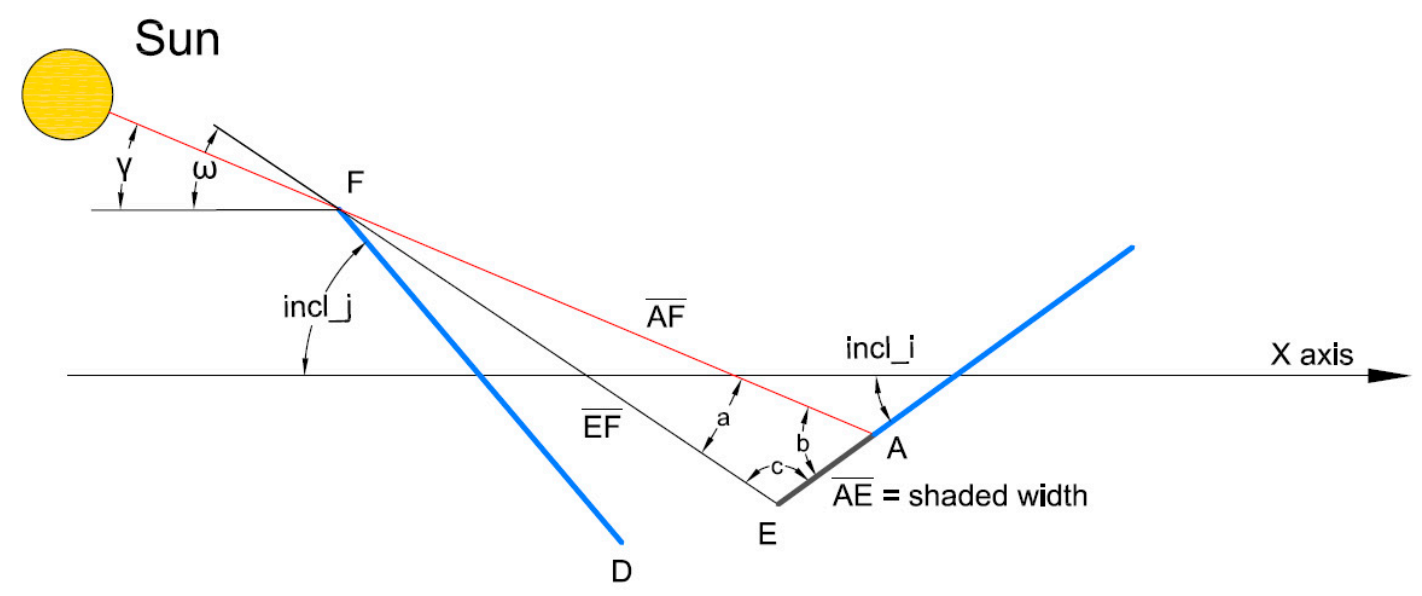

Figure 9. Mirror rows with a negative inclination and previous mirror rows with positive inclination.

Author Contributions: Regarding the contribution of each author to the article, the original idea and work coordination corresponded to F.J.S. and M.T.M. The analysis of data was carried out by I.M., J.I.A., F.J.L., M.M. and P.R. Finally, the wording of the conclusions was made by F.J.S.

Funding: This research was funded by Research, Development and Renewable energies for the improvement of business fabric in Centro, Extremadura and Alentejo Project (0330_IDERCEXA_4_E).

Acknowledgments: The authors would like to thank the Junta de Extremadura and FEDER (Fondo Europeo de Desarrollo Regional "Una manera de hacer Europa") for its support through the economic aid for research groups (GR18137), as well as Research, Development and Renewable energies for the improvement of business fabric in Centro, Extremadura and Alentejo Project (0330_IDERCEXA_4_E).

Conflicts of Interest: The authors declare no conflict of interest. 


\section{Abbreviations}

$\delta$

$\mu_{i}$

$\rho_{p r}$

$\rho_{s d}$

A

E

EE

$f_{c l \_p r}$

$f_{c l \_s d}$

$f_{n l p}$

$f_{o l}$

$f_{\text {shading }}$

$I_{b}$

i

inc

$L_{a}$

L

$n$

$r$

j

$R_{E C}$

$R_{S T}$

$R_{T E}$

$S P$

$t$

$T$

$T E$

$T P$

sw

Z

angle between normal vector row and $\mathrm{Y}$ axe $\left(^{\circ}\right)$

optical performance of LFC row

primary mirrors reflectance

secondary receiver reflectance

mirror row area of the LFC $\left(\mathrm{m}^{2}\right)$

monthly average concentrated energy ( $\mathrm{kWh}$ )

electrical energy $(\mathrm{kWh})$

primary mirrors cleanliness factor

secondary receiver cleanliness factor

non-lite pipe factor

optical losses factor

shadow between rows factor

beam irradiance $\left(\mathrm{kW} \mathrm{m}^{-2}\right)$

mirror rows

inclination angle $\left(^{\circ}\right)$

absorber tube length of the LFC (m)

mirror length of the LFC (m)

months of production

number of mirror rows

month

energy concentration ratio

solar time ratio

thermal energy ratio

production time during solar time (h)

calculation step

time step (h)

thermal energy (kWh)

total production time (h)

shaded width $(\mathrm{m})$

non-lite pipe $(\mathrm{m})$

\section{References}

1. International Energy Agency World Energy Outlook Spanish Translation. Available online: www.iea.org/t\&c/ (accessed on 22 February 2019).

2. Pavlovic, S.; Daabo, A.M.; Bellos, E.; Stefanovic, V.; Mahmoud, S.; Al-Dadah, R.K. Experimental and numerical investigation on the optical and thermal performance of solar parabolic dish and corrugated spiral cavity receiver. J. Clean. Prod. 2017, 150, 75-92. [CrossRef]

3. Abbas, R.; Martínez-Val, J.M. A comprehensive optical characterization of linear Fresnel collectors by means of an analytic study. Appl. Energy 2017, 185, 1136-1151. [CrossRef]

4. Tiwari, S.; Tiwari, G.N. Thermal analysis of photovoltaic thermal integrated greenhouse system (PVTIGS) for heating of slurry in potable biogas plant: An experimental study. Sol. Energy 2017, 155, 203-211. [CrossRef]

5. Agency Europe Enviromental The Increase in Energy Consumption Slows the EU's Progress on Renewable Energy and Energy Efficiency Goals. Available online: https://www.eea.europa.eu/es/highlights/el-aumentodel-consumo-de (accessed on 25 February 2019).

6. Wang, Y.; Lu, B.; Chen, H.; Fan, H.; Taylor, R.A.; Zhu, Y. Experimental investigation of the thermal performance of a horizontal two-phase loop thermosiphon suitable for solar parabolic trough receivers operating at 200-400 ${ }^{\circ}$ C. Energy 2017, 132, 289-304. [CrossRef]

7. Yuksel, Y.E.; Ozturk, M.; Dincer, I. Thermodynamic performance assessment of a novel environmentally-benign solar energy based integrated system. Energy Convers. Manag. 2016, 119, 109-120. [CrossRef]

8. Pulido-Iparraguirre, D.; Valenzuela, L.; Serrano-Aguilera, J.J.; Fernández-García, A. Optimized design of a Linear Fresnel reflector for solar process heat applications. Renew. Energy 2019, 131, 1089-1106. [CrossRef] 
9. Corona, B.; Cerrajero, E.; López, D.; San Miguel, G. Full environmental life cycle cost analysis of concentrating solar power technology: Contribution of externalities to overall energy costs. Sol. Energy 2016, 135, 758-768. [CrossRef]

10. Tsekouras, P.; Tzivanidis, C.; Antonopoulos, K. Optical and thermal investigation of a linear Fresnel collector with trapezoidal cavity receiver. Appl. Therm. Eng. 2018, 135, 379-388. [CrossRef]

11. Bellos, E.; Mathioulakis, E.; Tzivanidis, C.; Belessiotis, V.; Antonopoulos, K.A. Experimental and numerical investigation of a linear Fresnel solar collector with flat plate receiver. Energy Convers. Manag. 2016, 130, 44-59. [CrossRef]

12. Ellabban, O.; Abu-Rub, H.; Blaabjerg, F. Renewable energy resources: Current status, future prospects and their enabling technology. Renew. Sustain. Energy Rev. 2014, 39, 748-764. [CrossRef]

13. Tzivanidis, C.; Bellos, E.; Antonopoulos, K.A. Energetic and financial investigation of a stand-alone solar-thermal Organic Rankine Cycle power plant. Energy Convers. Manag. 2016, 126, 421-433. [CrossRef]

14. Deniz, E.; Çınar, S. Energy, exergy, economic and environmental (4E) analysis of a solar desalination system with humidification-dehumidification. Energy Convers. Manag. 2016, 126, 12-19. [CrossRef]

15. BP Energy Outlook 2019. Available online: https://www.bp.com/content/dam/bp-country/es_es/spain/ documents/downloads/PDF/bp-energy-outlook-2019_book.pdf (accessed on 26 March 2019).

16. Institute for Diversification and Saving of Energy. Final Energy Consumption. Available online: http: //sieeweb.idae.es/consumofinal/bal.asp?txt=2016\&tipbal=t (accessed on 28 February 2019).

17. Farjana, S.H.; Huda, N.; Mahmud, M.A.P.; Saidur, R. Solar process heat in industrial systems-A global review. Renew. Sustain. Energy Rev. 2018, 82, 2270-2286. [CrossRef]

18. Kalogirou, S.A. Solar thermal collectors and applications. Prog. Energy Combust. Sci. 2004, 30, $231-295$. [CrossRef]

19. Monreal, J.A.; Jaramillo, O.A. Design of a Solar Linear Fresnel Concentrator of Low Entalphy for Heat Processes; Universidad Veracruzana: Veracruz, Mexico, 2012.

20. El Gharbi, N.; Derbal, H.; Bouaichaoui, S.; Said, N. A comparative study between parabolic trough collector and linear Fresnel reflector technologies. Energy Procedia 2011, 6, 565-572. [CrossRef]

21. Rungasamy, A.E.; Craig, K.J.; Meyer, J.P. 3-D CFD Modeling of a Slanted Receiver in a Compact Linear Fresnel Plant with Etendue-Matched Mirror Field. Energy Procedia 2015, 69, 188-197. [CrossRef]

22. Lin, M.; Sumathy, K.; Dai, Y.J.; Wang, R.Z.; Chen, Y. Experimental and theoretical analysis on a linear Fresnel reflector solar collector prototype with V-shaped cavity receiver. Appl. Therm. Eng. 2013, 51, 963-972. [CrossRef]

23. Lancereau, Q.; Rabut, Q.; Itskhokine, D.; Benmarraze, M. Wind Loads on Linear Fresnel Reflectors' Technology: A Numerical Study. Energy Procedia 2015, 69, 116-125. [CrossRef]

24. Zhu, J.; Huang, H. Design and thermal performances of Semi-Parabolic Linear Fresnel Reflector solar concentration collector. Energy Convers. Manag. 2014, 77, 733-737. [CrossRef]

25. Sahoo, S.S.; Singh, S.; Banerjee, R. Analysis of heat losses from a trapezoidal cavity used for Linear Fresnel Reflector system. Sol. Energy 2012, 86, 1313-1322. [CrossRef]

26. Balaji, S.; Reddy, K.S.; Sundararajan, T. Optical modelling and performance analysis of a solar LFR receiver system with parabolic and involute secondary reflectors. Appl. Energy 2016, 179, 1138-1151. [CrossRef]

27. Haagen, M.; Zahler, C.; Zimmermann, E.; Al-Najami, M.M.R. Solar Process Steam for Pharmaceutical Industry in Jordan. Energy Procedia 2015, 70, 621-625. [CrossRef]

28. Buscemi, A.; Panno, D.; Ciulla, G.; Beccali, M.; Lo Brano, V. Concrete thermal energy storage for linear Fresnel collectors: Exploiting the South Mediterranean's solar potential for agri-food processes. Energy Convers. Manag. 2018, 166, 719-734. [CrossRef]

29. Zahler, C.; Iglauer, O. Solar process heat for sustainable automobile manufacturing. Energy Procedia 2012, 30, 775-782. [CrossRef]

30. Farjana, S.H.; Huda, N.; Mahmud, M.A.P.; Saidur, R. Solar industrial process heating systems in operation-Current SHIP plants and future prospects in Australia. Renew. Sustain. Energy Rev. 2018, 91, 409-419. [CrossRef]

31. Kumar, L.; Hasanuzzaman, M.; Rahim, N.A. Global advancement of solar thermal energy technologies for industrial process heat and its future prospects: A review. Energy Convers. Manag. 2019, 195, 885-908. [CrossRef] 
32. Jia, T.; Huang, J.; Li, R.; He, P.; Dai, Y. Status and prospect of solar heat for industrial processes in China. Renew. Sustain. Energy Rev. 2018, 90, 475-489. [CrossRef]

33. Schweiger, H.; Farinha Mendes, J.; Benz Bayr, N.; Hennecke, K.; Prieto, G.; Cusí, M.; Gonçalves, H. A state of the art review for Spain and Portugal. In Proceedings of the Potential of Solar Heat in Industrial Processes, Kopenhagen, Denmark, 19-22 June 2000.

34. Lauterbach, C.; Schmitt, B.; Jordan, U.; Vajen, K. The potential of solar heat for industrial processes in Germany. Renew. Sustain. Energy Rev. 2012, 16, 5121-5130. [CrossRef]

35. National Geographic Institute Sunrise and Sunset for the Year 2017 in Cáceres. Available online: https: //www.fomento.gob.es/salidapuestasol/2017/Caceres-2017.txt (accessed on 9 May 2019).

36. MathWorks. MATLAB. Available online: https://es.mathworks.com/products/matlab.html (accessed on 9 May 2019).

37. Pino, F.J.; Caro, R.; Rosa, F.; Guerra, J. Experimental validation of an optical and thermal model of a linear Fresnel collector system. Appl. Therm. Eng. 2013, 50, 1463-1471. [CrossRef]

38. Meteotest, A.G. Meteonorm. Available online: https://meteonorm.com (accessed on 9 May 2019).

39. Kincaid, N.; Mungas, G.; Kramer, N.; Wagner, M.; Zhu, G. An optical performance comparison of three concentrating solar power collector designs in linear Fresnel, parabolic trough, and central receiver. Appl. Energy 2018, 231, 1109-1121. [CrossRef]

40. Ahmed, M.H.; Rady, M.; Amin, A.M.A.; Montagnino, F.M.; Paredes, F. Comparison of thermal and optical performance of Linear Fresnel and Parabolic Trough Concentrator. In Proceedings of the 2015 International Conference on Renewable Energy Research and Applications, ICRERA 2015, Institute of Electrical and Electronics Engineers Inc., Palermo, Italy, 22-25 November 2015; pp. 626-629.

41. Ghodbane, M.; Boumeddane, B.; Said, Z.; Bellos, E. A numerical simulation of a linear Fresnel solar reflector directed to produce steam for the power plant. J. Clean. Prod. 2019, 231, 494-508. [CrossRef]

(C) 2019 by the authors. Licensee MDPI, Basel, Switzerland. This article is an open access article distributed under the terms and conditions of the Creative Commons Attribution (CC BY) license (http://creativecommons.org/licenses/by/4.0/). 